\title{
TERESA FILÓSOFA: “FILOSOFIA” E EROTISMO NA FRANÇA
}

\author{
Marcelo Costa ${ }^{1}$
}

\section{RESUMO}

Este artigo pretende demonstrar a importância das obras produzidas no século XVIII, na França, chamadas "filosóficas", ou seja, publicações não-autorizadas que eram distribuídas por meio de contrabando e tinham um alto índice de leitores. Os livros "filosóficos" tratavam de erotismo, pornografia, anticlericalismo e criticavam o Antigo Regime. O foco deste texto é dado à obra Thérèse philosophe ou mémoires pour servir à l'histoire du père Dirrag et de mademoiselle Eradice, considerada por muitos como o maior clássico pornográfico da França setecentista, de autor desconhecido. A abordagem do livro revela-se precursora do discurso feminista do século $\mathrm{XX}$, em que é requisitado à mulher o direito sobre seu corpo.

Palavras-chave: História; Literatura; Censura; Feminismo.

\begin{abstract}
The aim of this paper is to show the importance of literary works produced in the eighteenth century in France called "philosophical", i.e., unauthorized publications that were distributed illicitly and had a high quantity of readers. The "philosophical" books dealt with eroticism, pornography, anticlericalism and criticized the Ancien Régime. The main focus of this paper is the novel "Thérèse philosophe or memoires pour l'histoire du serve Dirrag père et de mademoiselle Eradice", written by an unknown author, considered the greatest classic porn of eighteenth-century France. The book's approach proves to be a precursor of feminist discourse of the twentieth century, which gives women the right over their body.
\end{abstract}

Keywords: History, Literature, Censorship, Feminism.

O século XVIII, quando analisado pelo prisma das narrativas - notadamente dos romances -, foi um momento de grandes transformações. Os autores demonstravam ter percepção das mudanças que estavam ocorrendo e uma intelligencia assume para si o papel de instruir o público. Nesse contexto, os romances foram o meio pelo qual esta intelligencia divulgava suas idéias. (MARQUES, 2009, p. 6)

O presente artigo busca, por meio da obra Teresa Filósofa, refletir sobre o papel das publicações "filosóficas” na disseminação de ideias revolucionárias no século XVIII.

\footnotetext{
${ }^{1}$ Advogado, especialista em auditoria e graduando do curso de História - Memória e Imagem da Universidade Federal do Paraná (UFPR).
} 
A obra Thérèse philosophe ou mémoires pour servir à l'histoire du père Dirrag et de mademoiselle Eradice, considerada por muitos como o maior clássico pornográfico da França setecentista, foi escrita por volta de 1748 (data da primeira publicação) e trata da educação sexual e filosófica de Teresa, da infância até o seu defloramento. A obra tem caráter libertino, no sentido que Trousson (1996) dá ao termo, ou seja, de transgressão; transmite a idéia de ser um "empreendimento de liberação, nem que seja pela reabilitação do prazer contra as proibições: libertinos e libertários se juntam.” (TROUSSON, 1996, p. 167)

Em relação ao termo "pornográfico", este não era utilizado à época. O termo e a noção que o cerca surgiram no século XIX. No século XVIII, estes livros faziam parte do grande grupo dos "livros filosóficos", que englobava ficção erótica, pornografia pura, panfletos anticlericais, críticas ao Regime, dentre vários outros gêneros.

Assim, podemos perceber que o termo "filosofia" na França do século XVIII tinha um sentido diferente do que utilizamos atualmente. Para Trouson, aqueles que serão os chamados "filósofos" eram todos os considerados libertinos, com espírito forte, os livres-pensadores. O termo libertino era utilizado inicialmente para todos aqueles que pensavam ou agiam contra os costumes ou contra a ordem social vigente. (TROUSSON, 1996, p. 166)

Para aqueles que trabalhavam com livros, o que se entendia por "filosofia" no Antigo Regime não era o pensamento iluminista, mas sim o dos livros ilícitos, dentre estes os pornográficos - caso de Teresa Filósofa. O depoimento de um livreiro da época, Hubert Cazin, ao ser questionado sobre o termo "artigos filosóficos" nos dá confirmação deste entendimento: "expressão [...] convencionada no comércio do livro para caracterizar tudo o que [é] proibido." (DARNTON, 1992, p. 18).

Além disso, este termo é utilizado também em catálogos que circulavam no período oferecendo este tipo de produto. São documentos ilegais que circulavam "por debaixo do pano", "tal qual os livros que arrola ou anuncia. Seu título é eloqüente: Livres philosophiques [Livros filosóficos]"(IDEM, p. 13). Desse modo, o termo "filosofia", para o século XVIII, abrangia as áreas mais diversas. Significava aquilo que "contesta todas as ortodoxias religiosas, filosóficas, políticas -; zomba dos valores sagrados da Igreja e do Estado; cobre de ridículo as personagens mais bem situadas na hierarquia social; e, para terminar, respinga lama na monarquia." (IDEM, p. 160).

No Antigo Regime, a legislação aplicável ao setor livreiro distinguia em três categorias os livros proibidos: "os que ofendiam a Igreja, os que ofendiam o Estado e aqueles que atentavam contra a moralidade.” (DARNTON, 1998, p. 104) 
No Brasil do século XIX, os livros pornográficos que circulavam pelo Rio de Janeiro eram conhecidos como "romances para homens, textos direcionados exclusivamente para o público masculino, em função de seu apelo sexual e caráter proibitivo.” (SILVA, 2006, p. 191). Os que vivem do comércio de livros proibidos têm consciência do risco que correm, visto que a polícia constantemente faz apreensões em lojas, prisão de livreiros, etc. No entanto, isto não os impede de negociar com as obras proibidas.

O sistema de publicação dos livros "filosóficos" funciona como um sistema de trocas entre as grandes editoras e os pequenos livreiros ou editores. As mais importantes procuram não imprimir muitos livros chocantes, elas trocam com estes pequenos editores que fazem a impressão dos livros proibidos e, em troca de outras edições proibidas ou não, repassam para as grandes distribuírem. Estes pequenos editores são os que efetivamente se arriscam a trabalhar na publicação de livros proibidos: "essa arraia-miúda, composta de chefes de tipografia, caixeiros de loja, donos de colégio, pequenos livreiros e aventureiros intelectuais, publicou boa parte da literatura mais ousada de seu século." (DARNTON, 1992, p. 22). A contabilidade da troca funciona folha por folha, "à maneira de Liège", havendo, no entanto, um "câmbio", normalmente uma folha de livro proibido contra duas do livro autorizado. "O sistema recompensa o risco, e todos têm o seu ganho (IDEM, 1992, 24)".

A distribuição acontece por meio de divulgação em catálogos, sendo que cada editor possui dois: um para os livros autorizados, com seu nome e endereço, e outro, sem nenhuma identificação, além de "Livros filosóficos". O preço do livro será determinado por diversos fatores, como por exemplo, a notoriedade do título ou do autor e ilustração. Além disso, o custo do transporte, os riscos envolvidos e o lucro do livreiro podiam fazer o valor do livro dobrar. Mas isso não impedia as pessoas mais pobres de lerem, quem não os podia comprar, lia nos gabinetes literários.

O transporte também tem seus truques, como, por exemplo, o "casamento" do livro, que é misturar folhas de uma obra em outra; o empacotamento, no qual cada livreiro tem suas táticas para despistar a alfândega ou a polícia; e o contrabando profissional, conhecido também como "seguro", em virtude de que se os livros forem confiscados o segurador paga a fatura.

Este contrabando iria abastecer, não só a França; verifica-se também o mesmo expediente para o abastecimento de outros países, como Portugal, onde "os livros eram conseguidos por meios de viajantes, diplomatas, além do contrabando, puro e simples" (DeNIPOTI, 2008, p. 433). 
No comércio dos livros "filosóficos" no período, quatro grupos atuam, possibilitando a disseminação dos livros proibidos pelo maior espaço geográfico possível: o vendedor ambulante; o dono de loja, que mantém os gabinetes literários; o grande e o médio livreiros estabelecidos: "cada qual encarna uma etapa da difusão do livro proibido, que vai das artérias aos capilares do circuito clandestino.” (DARNTON, 1992, p. 96).

Segundo Darnton, os livros "filosóficos” possuíam, no Antigo Regime, um esquema próprio de publicação, circulação e comércio, "que atrai para si os livros mais proibidos nos quatro cantos do reino.” (p. 127)

A publicação de Thérèse Philosophe (1748) ocorreu num momento em que se iniciava a divulgação das obras iluministas de Montesquieu, Rousseau, Diderot, sendo parte deste momento de efervescência, de transformação da intelectualidade francesa, cujos adeptos eram chamados de libertinos. Thérèse pertence a este "mundo lascivo, indecente, atrevido dos primórdios do Iluminismo, onde se questionava tudo e nada era sagrado." (DARNTON, 1998, p. 106)

Outro ponto que aproxima a obra do Iluminismo é que o corpo humano, quando descrito ou objeto de reflexão, é tratado como máquina utilizando-se termos como “mecânica”, “fluídos”; “minha máquina”. Para Darnton, "Thérèse fala a mesma língua de Diderot, d'Holbach e La Mettrie", sendo este último autor de L'homme-machine publicado no mesmo ano. (DARNTON, 1998, p.118)

A autoria da obra ainda é uma incógnita, tendo já sido atribuída a Diderot e a D’Arles de Montigny. No entanto, o mais provável autor seria o Marquês D’Argens, Jean-Baptiste de Boyer, "aristocrata de fé protestante, com interesses filosóficos e reputação de devasso" (MARQUES, 2008, p. 1). Nas capas do livro, nas diversas edições que conseguimos visualizar, percebe-se esta confusão, aparecendo em algumas como autor anônimo, Marques D’Argens ou Diderot.

Para Alves (2004), o título do livro Thérèse Philosophe seria uma crítica às mulheres filósofas da época, pois durante a maior parte do texto a reflexão é masculina e o aprendizado filosófico para as mulheres se mostra somente possível pela via sexual. Isto em um período e num lugar (França) em que "a presença e as reivindicações femininas são significativas para as construções filosóficas e literárias dos 'homens iluminados"” (p. 8).

No entanto, Darnton defende que a obra tem um lugar de destaque na história da emancipação da mulher, ao expor uma sensualidade feminina que não se subordina aos prazeres e desejos masculinos: "recusando-se o papel de esposa respeitável e mãe de família, 
Thérèse abre uma brecha no conformismo social e na função que aquele destina à mulher". (DARNTON, 1992, p.168)

Escrito na primeira pessoa, em forma de carta, a pedido de seu amante que considera que esta estaria fazendo um bem à humanidade, o livro congrega o sexual e o espiritual, mesclando partes com descrição de cenas libidinosas envolvendo ou não Teresa e discussões filosóficas sobre a Igreja, o prazer, o pecado, a bondade de Deus, maternidade, masturbação, e muitos outros assuntos. O leitor é convidado a participar da trama como voyeur, sendo que as ilustrações auxiliam na identificação do leitor com esta característica da obra.

O principal alvo de crítica do autor é o clero, o qual aparece em diversas cenas sexuais e nas discussões filosóficas, no entanto com diferença de tratamento: Dirrag é um devasso e aproveitador; o Abade C. é quem ensina a Teresa o caminho do bem. A nobreza é mais bem tratada pelo autor. Esta crítica à Igreja e o questionamento de dogmas da religião, principalmente dos relacionados ao prazer e à capacidade humana, evidenciam o seu o caráter iluminista, na busca de "por fim a preconceitos e difundindo o conhecimento, abrir espaço para uma nova ética" (RIBEIRO, 1996, p. 225).

Outro ponto de grande preocupação presente no livro, que pode ser um reflexo dos problemas do seu tempo, é a questão da contracepção, do controle de natalidade. As mulheres têm uma preocupação sempre presente em não engravidar, e este risco é explicitado pelo Abade T, quando afirma que "as mulheres têm somente três coisas a temer: o medo do diabo, a reputação e a gravidez" (Teresa Filósofa, p. 82). O risco da gravidez para a mulher não era somente o da reputação, mas de saúde, pois inúmeras delas morriam em consequiência da gravidez, perdiam seus filhos (como Mme. M) ou adoeciam (como a mãe de Teresa).

A essa questão está relacionada também a elegia que se faz da masturbação em todo o livro: além se ser uma forma de aplacar o desejo, serve como contraceptivo natural. Além da masturbação, o coito interrompido também é defendido como ação que pode ser utilizada para evitar os riscos de uma gravidez; não se verifica é a discussão sobre o uso de preservativo, o que já era conhecido à época.

Teresa, desde o começo, já deixa claro qual é o seu recado para o leitor ao refletir, no segundo capítulo, sobre a origem das paixões humanas: "Imbecis mortais! Acreditais ser mestres em extinguir as paixões que a natureza colocou em voz: elas são a obra de Deus." (Teresa Filósofa, p. 28)

A história pode ser dividida em cinco partes: o início da vida de Teresa e os seus primeiros contatos com o sexo; o seu envolvimento no caso Padre Dirrag-Mademoiselle 
Eradice; o seu aprendizado junto ao Abade T. e Mme. C.; sua vida em Paris e as histórias picantes de Mme. Bois-Laurier; e por fim, seu envolvimento com o conde e finalmente... o seu defloramento. Para RIBEIRO:

Este é um romance que tem um tema e uma meta, o defloramento. Tudo caminha para essa finalidade, que deixa assim de ser o destino de toda mulher, primeiro, um perigo, portanto recusado, e - depois uma opção, até mesmo uma festa. (RIBEIRO, 1996, p.219)

No que definimos como a primeira parte, que vai do nascimento de Teresa até sua saída do convento, a heroína é apresentada ao leitor, desde antes de sua concepção apresentando seu pai e sua mãe, passando pela sua descoberta da masturbação, das diferenças entre homens e mulheres, até sua ida para um convento do qual sairá aos 23 anos. Esta parte é marcada pela culpa cristã e pelo pecado, tanto por parte da mãe, como da própria Teresa, em relação ao prazer sexual, bem como pelas discussões de Teresa sobre a predestinação e o livre-arbítrio.

Pode-se perceber, nesta parte, o quanto os conceitos religiosos estão arraigados nesta sociedade pré-revolucionária. Após sua primeira confissão, na qual seu confessor lhe demonstra o quanto a masturbação é pecaminosa - "o mais infame dos vícios" - e Teresa contar sobre suas brincadeiras com as outras crianças, ela declara que "pela primeira vez, acreditei perceber um crime em nossos prazeres. (...) Depois disso ele me mandou combater as minhas paixões com as armas do jejum, da prece e do cilício.” (Teresa Filósofa, pp. 33-34)

A segunda parte é destinada ao relato do caso Padre Dirrag-Eradice, no qual um padre jesuíta seduz uma devota utilizando-se de subterfúgios como um famoso cordão de São Francisco. Segundo DARNTON, os nomes eram um anagrama e os leitores da época reconheciam na história uma situação muito famosa e semelhante envolvendo Catherine Cadière e Jean-Baptiste Girard (DARNTON, 1998, p. 107). Tanto a narradora quanto sua amiga Eradice buscam um êxtase religioso - uma referência implícita à Santa Teresa de Ávila e seu êxtase demonstrado na estátua de Bernini.

Este trecho da obra é uma crítica explícita à Igreja, principalmente quanto aos abusos em nome da fé na busca de vantagens pessoais, inclusive sexuais. A reflexão de Teresa nesta parte centra-se no abuso que o padre Dirrag faz das coisas mais respeitáveis da sociedade: a crença da devota; a disciplina; as relíquias santas. O autor relaciona diretamente o jesuitismo e a sodomia, quando relata: "ele ousou dirigir várias vezes a cabeça do instrumento para a 
porta favorita, na qual esbarra levemente. Mas, enfim, a prudência predominou sobre o gosto." (Teresa Filósofa, p. 51)

A parte que trata da educação de Teresa realizada com base nos ensinamentos do Abade C. e de Mme. M. é aquela na qual são realizadas as principais discussões filosóficas do livro e na qual Teresa descobre que a masturbação não é pecado. Nas palavras do Abade C.: "como ousaríamos temer ofender a Deus aliviando as nossas necessidades por meios que Ele pôs em nós, que são obra sua." (Teresa Filósofa, p.72).

Uma das reflexões filosóficas do Abade C., que Teresa escuta escondida, talvez uma das mais interessantes, se refere às religiões. $\mathrm{O}$ autor apresenta inúmeros argumentos contra a doutrina católica; muitos destes argumentos, segundo DARNTON (1998, p. 123), foram retirados de um panfleto que circulou no ano de 1745 Examen de la religion dont on cherche l'éclaircissement de bonne foi. Entre estes, um define como esta obra é um resultado do seu tempo: "Ele [Deus] me deu a razão para eu me servir dela." (Teresa Filósofa, p. 94).

A quarta parte da obra, em que Teresa vai para Paris, é iniciada por uma crítica aos banqueiros que aparecem como seres sem qualquer tipo de moral, sendo que um deles tenta violentar Teresa. É um contraponto ao conde, que aparecerá ainda nesta parte e que se comporta como um honnête homme.

$\mathrm{Na}$ última parte, na qual Teresa se entrega ao Conde, após a leitura de livros "filosóficos", percebe-se que, apesar da impossibilidade do casamento entre os dois, em virtude dos diferentes níveis sociais, tal idéia não impede a heroína a buscar o prazer e este prazer é alcançado com o cuidado de não engravidar, um dos principais riscos de morte para a mulher no período: o coito interrompido cuida para que os amantes vivam até o momento da obra por dez anos, sem o perigo de uma gravidez.

A obra apresenta uma crítica fortíssima à instituição Igreja, estando padres, abades e outros clérigos envolvidos em diversas situações relacionadas ao sexo, bem como sendo discutidas diversas questões como o pecado, as religiões, dentre outros assuntos. Para MARQUES, “como afronta a Igreja, o relato de Teresa adquire, deste modo, caráter exemplar de uma nova moral" que é a de procurar a felicidade na vida terrena, residindo ai "a verdade que Teresa pretende expor.” (MARQUES, 2008, p. 4)

Para HOUBRE (2003, p. 100), “além de um relato cruamente explícito da iniciação sexual (...) [é veículo] de idéias subversivas para a sociedade do século XVIII”: a questão da 
virgindade pré-nupcial; a instituição marital; a finalidade marital; e por fim a finalidade reprodutora da sexualidade.

Assim, as discussões filosóficas que são realizadas pelo autor, entremeadas por diversos tipos de práticas sexuais, são assuntos presentes nas discussões do Iluminismo, sendo a libertinagem presente na obra também uma forma de contestação ao status quo. Para MARQUES (2008, p. 2), “o que se debatia, de fato, era a relação direta entre a moral individual e a moral religiosa".

No final Teresa faz um resumo de todos os pontos que apresentou durante o livro, considerando tudo, inclusive o sexo, obra de Deus, e que "a razão nos esclarece, mas em nada nos determina”, pois Deus é soberano e perfeito. (Teresa Filósofa, p. 163).

A última frase do livro esclarece que o objetivo do autor não foi atacar nem a nobreza, nem o rei; fica evidente que o seu objetivo estava centrado no clero e nas finanças: "Enfim, os reis, os príncipes, os magistrados, todos os diversos superiores, por gradações, que cumprem os deveres do seu estado devem ser amados e respeitados, porque cada um deles age para contribuir para o bem de todos." (Teresa Filósofa, p. 163)

Concluindo, podemos perceber que na disseminação das ideias revolucionárias no século XVIII os livros ilícitos, as chamas obras "fillosóficas", tiveram papel importante, visto que uniam a reflexão sobre os ideais do Iluminismo, com algo extremamente popular, o sexo, o que permitia a circulação das ideias entre as diversas classes sociais. 


\section{BIBLIOGRAFIA}

ALVES, Adriana D. R. O "best-seller proibido" Thérèse Philosophe: releitura a partir do conceito de gênero Disponível em http://www.uesb.br/anpuhba/artigos/anpuh_II/adriana_dantas_reis_alves.pdf $>$ Acesso em 03 jun.2010.

DARNTON, Robert. Edição e sedição: o universo da literatura clandestina no século XVIII. São Paulo: Companhia da Letras, 1992.

DARNTON, Robert. Pornografia filosófica. IN: Os best-sellers proibidos da França prérevolucionária. São Paulo: Companhia da Letras, 1998. P. 101-130.

DeNIPOTI, Cláudio. Comércio e circulação de livros entre França e Portugal na virada do século XVIII para o XIX ou Quando os ingleses atiraram livros ao mar Disponível em < http://www.scielo.br/scielo.php?script=sci_arttext\&pid=S0102-01882008000200008 > Acesso em 24 mai.2010.

HOUBRE, Gabrielle. Inocência, saber, experiência: as moças e seu corpo - fim do século XVIII/começo do século XIX. IN: MATOS, Maria I. S. de, SOIHET, Rachel (org.) O corpo feminino em debate. São Paulo: Editora UNESP, 2003. P. 93-106.

MARQUES, Mariana T. Teresa Filósofa e Fanny Hill, romances filosóficos? Disponível em $<$

http://www.abralic.org/anais/cong2008/AnaisOnline/simposios/pdf/049/MARIANA_MARQ

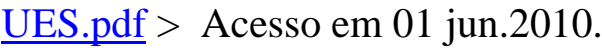

MARQUES, Renato S. Da "ladra" de Defoe à "princesa" de Voltaire: Diferentes formas de se construir a imagem da mulher em livros setecentistas. Disponível em < http://www.uff.br/lihed/segundoseminario/index.php/resumos/por-autor-prenome/97-de-r-a$\mathrm{z}$ ?lang=pt $>$ Acesso em 22 mai.2010.

RIBEIRO, Renato J. Literatura e erotismo no século XVIII francês: o caso de Teresa Filósofa. IN: NOVAES, Adauto (org.) Libertinos libertários. São Paulo: Companhia das Letras, 1996. P. 219-230.

SILVA, Maurício. Resenha de: EL FAR, Alessandra. Páginas de Sensação: Literatura popular e pornográfica no Rio de Janeiro (1870-1924). Disponível em < http://www.historiaimagem.com.br/edicao4abril2007/elfar.pdf > Acesso em 25 mai.2010.

TERESA FILÓSOFA. Tradução de Maria Carlota Carvalho Gomes. Porto Alegre: L\&PM, 2000.

TROUSSON, Raymond. Romance e libertinagem no século XVIII na França. IN: NOVAES, Adauto (org.) Libertinos libertários. São Paulo: Companhia das Letras, 1996. P. 165-183. 